\title{
Pensando los públicos desde la educación artística y las políticas culturales
}

\section{Thinking audiences from artistic education and cultural policies}

Gonzalo Vicci ${ }^{1}$ 


\section{Resumen}

Para pensar hoy la formación de públicos en artes escénicas, resulta necesario posicionarse desde un lugar que ponga en juego algunos elementos que habitualmente se sitúan por fuera de los estudios teatrales. La educación artística y la posibilidad de colocar la atención en los sujetos que conforman los diferentes públicos, constituye un abordaje necesario al momento de pensar otras perspectivas de trabajo en relación a la producción escénica. Deberíamos entonces, poner atención en los procesos que se suceden al momento de que esas producciones se vinculan con diferentes públicos, de alguna manera subvertir las miradas y volverlas hacia esos individuos que no conocemos y que no son uniformes. Este texto intenta plantear algunas perspectivas que aportan a la reflexión en torno al diálogo entre la educación vinculada con las artes escénicas y las políticas culturales, tomando como eje la experiencia de los públicos y su relación con las producciones artísticas.

Palabras-clave: Educación artística; públicos; artes escénicas

\section{Abstract}

To think today about the formation of audiences in performing arts, it is necessary to position oneself from a place that brings into play some elements that are usually located outside the theatrical studios. Artistic education and the possibility of placing attention on the subjects that make up the different audiences constitutes a necessary approach when thinking of other perspectives of work in relation to stage production. We should therefore pay attention to the processes that take place when these productions are linked to different audiences, in a way subvert the gazes and turn them towards those individuals we do not know and who are not uniform. This text tries to put forward some perspectives that contribute to the reflection on the dialogue between education linked to the performing arts and cultural policies, taking as its axis the experience of audiences and their relationship with artistic productions.

Keywords: Artistic education; audiences; performing arts 
Los enfoques vinculados a los públicos y las artes escénicas remiten a diversos autores que muchas veces entran en contradicción en cuanto a la manera de relacionar el hecho artístico con quien se acerca a él. Seguramente esto se debe a la diversidad de posicionamientos y discursos que existen en relación al arte y sus condiciones de producción, exposición y relación con los públicos. Las artes escénicas, así como las artes visuales contemporáneas, han generado formas expresivas, creativas y de lenguajes múltiples que enredan y confunden las modalidades tradicionales de las artes escénicas y visuales, al tiempo que las solapan y difunden su influencia con otras formas quizás vinculadas a la comunicación, la publicidad, etc. ${ }^{2}$

De la misma forma, desde la segunda mitad del siglo XX hasta la actualidad, hemos presenciado la multiplicación de las condiciones de pertenencias identitarias, sociales y culturales que definen las probables maneras de construir narrativas relacionadas con las obras artísticas.

El público ya no puede ser concebido, con relación al arte, bajo condiciones de totalidad y pasividad, sino en términos de lógicas múltiples de construcción de identidad y participación activa en la apreciación e interpretación del fenómeno artístico.

De esta manera, es necesario formular algunas preguntas que nos permitan reflexionar acerca de las condiciones de formación y circulación de los públicos vinculados a las artes escénicas, en particular desde una mirada localizada, situada geográficamente al sur del sur, en el Río de la Plata. Parto de la idea de que las políticas públicas en relación a la cultura determinan estos flujos y condicionan, positiva y negativamente según el caso, las posibilidades de ampliar las vías de entrada, estudio, abordaje y desarrollo de estos temas. De la misma manera entiendo que la educación artística, desde su concepción más amplia y no sólo la relacionada con la practica artística, resulta una herramienta válida para dialogar y trabajar en este escenario.

\section{Algunas preguntas}

¿Quiénes son aquellos que pueden acceder a un teatro? Cuándo acceden, ¿en qué condiciones lo hacen? ¿De qué manera la educación artística puede contribuir a la conformación del gusto a través y para una propuesta de artes escénicas?

Una forma posible de responder estas preguntas, puede ser a través del concepto de habitus de Pierre Bourdieu (2003; 2010). Para este investigador, las clases sociales se distinguen por su posición en la estructura de producción y por la forma como se producen y distribuyen los bienes materiales y simbólicos en una sociedad. Es decir, en la línea de interrelación de lo económico con lo simbólico, la circulación y el acceso a estos bienes no se explica sólo por la pertenencia a una clase social, sino también por la diferencia que se engendra en lo que se considere como digno de transmitir o poseer. En la medida en que existe una correlación entre posición de clase y cultura, dos realidades de relativa autonomía, las relaciones de poder se confirman, se reproducen y renuevan. Esto conformaría un sistema de circulación de

2 Teniendo en cuenta el desarrollo del tema a nivel local y el trabajo realizado en los últimos años en este campo, se incluyen en este trabajo referencias y textos publicados oportunamente en: VICCI, Gonzalo. Formación de públicos y artes escénicas: una mirada hacia Montevideo. Congreso IberoAmericano de Ciencia, Tecnologia, Innovación y Educación. Buenos Aires (AR), 2014, p. 1-15. 
esos bienes simbólicos donde a cada sujeto ocupa un lugar signado por su experiencia. En la misma línea Jiménez (2000, p. 77) sostiene:

La disposición y la posibilidad de disfrute de este tipo de expresiones culturales parece estar circunscrita cada vez más a ciertos grupos sociales que tienen el precedente cultural, los antecedentes familiares, los estudios, así como los ingresos y el tiempo suficientes para incorporar estas prácticas a sus hábitos de uso del llamado tiempo libre.

De esta forma la noción planteada en relación a las condiciones y posibilidades de acceso a los bienes culturales se torna preponderante en el sentido de colocarse como sistema que facilita o inhibe la experiencia.

Sin embargo, si entendamos que las experiencias sociales no son homogéneas, podemos poner en discusión lo planteado por Bourdieu y coincidir con Bernard Lahire $(2012$, p. 72$)$, cuando sostiene que:

Hay varios problemas con esa definición. El primero es la idea de "sistema". Bourdieu sostenía que el conjunto de disposiciones conforma un sistema, que las disposiciones están todas ligadas entre sí y que se transfieren de una situación a otra. El mismo habitus actúa en circunstancias muy diferentes. Esto supone la homogeneidad de las experiencias socializadoras comunes. Mi primer problema es justamente con esa homogeneidad. Yo sostengo que al observar el mundo social uno se da cuenta de que existen un millón de experiencias socializadoras que son heterogéneas y que, incluso, pueden ser contradictorias entre sí. Esto quiere decir que no tenemos incorporado un sistema coherente y homogéneo de disposiciones que puede transferirse para todos lados, sino que somos el producto de disposiciones heterogéneas y muchas veces contradictorias. [...]. El segundo problema es que Bourdieu habla de "transferibilidad" del habitus y toma esa noción de Piaget, quien pensaba que los esquemas de pensamiento y de sentimiento se transferían de una situación a otra. Entonces, las dos cosas que señalo están relacionadas: si tenemos un sistema de disposiciones heterogéneas, no son las mismas disposiciones las que se transfieren de una situación a otra. Según la situación en la cual nos encontremos, ciertas disposiciones van a actuar, algunas se van a inhibir y otras se van a activar. Eso es el "hombre plural".

Esta objeción que realiza Lahire al planteo de Bourdieu ofrece un enfoque que amplía la perspectiva de análisis, tomando en cuenta la complejidad de lo contemporáneo, exigiendo volver a examinar la perspectiva teórica referida a los modos de apropiación simbólica, su circulación y re-significación.

Además, propone pensar la controversia entre cultura legítima vs. cultura popular, tomando como premisa básica que la situación ha cambiado drásticamente

Antes, la música clásica estaba en la cúspide, luego venía la literatura, especialmente la poesía. La ópera iba después de la música clásica porque los instrumentos eran más que la voz. Y las cosas iban así. Había además pocos productos culturales. Pocas cosas con las cuales distinguirse. Pero hoy esas jerarquías se debilitan porque hay más gente que puede acceder a esos productos. Yo pienso que la cultura legítima se ve debilitada por el aumento de las artes. (Lahire, 2012, p. 74)

Al poner el énfasis simultáneamente en la perspectiva individual y colectiva para trabajar desde la experiencia estética, como momento de transformación, la mirada relacionada con las posibilidades de relacionarnos con las producciones artísticas o 
artefactos culturales a partir de nuestros cumulados simbólicos se encuentra con la mirada planteada desde los estudios culturales, cuando sostienen que

\begin{abstract}
Para algunos, los relativamente "faltos de poder" pueden sacar fuerzas de su cultura y de ese modo enfrentar el ataque de los poderosos. Para otros, el contenido de la cultura misma carece prácticamente de pertinencia, lo importante es que esta refuerce una política con vistas al cambio. Aunque estas opiniones sean muy atractivas, también es cierto que la expresión cultural per se no basta. Digamos que ayuda a participar en la lucha cuando uno conoce cabalmente las complejas maquinaciones implícitas en apoyar una agenda a través de una variedad de instancias intermedias, situadas en distintos niveles, que a su vez tienen agendas similares, yuxtapuestas o discrepantes. Quienes se dedican a los estudios culturales a menudo consideran la agencia cultural de un modo más circunscrito, como si la expresión o identidad de un individuo o grupo en particular condujera, en sí mismo, al cambio. Sin embargo, según señala Iris Marion Young (2000), "nos encontramos posicionados en relaciones de clase, género, raza, nacionalidad, religión, etc. [dentro de "una historia ya dada de significados sedimentados, paisaje material e interacción con otros en el campo social"] que son fuente tanto de posibilidades de acción cuanto de coacción. (Yúdice, 2002, p. 15)
\end{abstract}

Yúdice también plantea una mirada crítica en relación a los discursos institucionales que remiten a la accesibilidad cultural y a la democratización de la cultura como eje principal de sus acciones, poniendo en cuestión la utilización del concepto de recurso cultural, al plantear que

....absorbe y anula las distinciones, prevalecientes hasta ahora, entre la definición de alta cultura, la definición antropológica y la definición masiva de cultura. La alta cultura se torna un recurso para el desarrollo urbano en el museo contemporáneo (por ejemplo, el Guggenheim de Bilbao). Los rituales, las prácticas estéticas cotidianas tales como canciones, cuentos populares, cocina, costumbres y otros usos simbólicos son movilizados también como recursos en el turismo y en la promoción de industrias que explotan el patrimonio cultural. (Yúdice, 2002, p. 16)

Si bien las definiciones de políticas culturales pueden variar de acuerdo a diversos autores y emplazamientos, me interesa subrayar la idea de Yúdice, en cuanto a que las políticas culturales en la contemporaneidad están asociadas a una noción de lo cultural como recurso económico, social, cultural o político e incluso una mixtura de todos:

La política cultural se encarna en guías para la acción sistemáticas y regulatorias que adoptan las instituciones a fin de alcanzar sus metas. En suma, es más burocrática que creativa u orgánica: las instituciones solicitan, instruyen, distribuyen, financian, describen y rechazan a los actores y actividades que se hallan bajo el signo del artista o de la obra de arte mediante la implementación de políticas. (Miller, Yúdice, 2004, p. 14)

Desde esta perspectiva, estás políticas culturales determinan la ausencia de enfoques que aborden la influencia y determinación que ellas tienen en relación a la construcción de las subjetividades.

Dicho de otra manera, se hace evidente que, de forma implícita, las políticas culturales son una herramienta de construcción de un determinado tipo de ciudadano, moldeado de acuerdo a los intereses que diagramen ese repertorio de guías de acción. 
Este enfoque de las políticas públicas, se hace evidente en su tendencia a construir permanentemente discursos en relación a lo que debe ser visto y no tanto sobre las formas en que estas producciones se relacionan con los públicos.

De esa forma se construye una especie de mercado, paralelo al comercial, que negocia e impulsa formas de ver y ser espectador pero sin profundizar en los mecanismos de vinculación entre lo que se produce y quien lo ve o puede llegar a verlo o vincularse con él.. Cuando el Estado, tiene a su cargo salas, elencos y fondos concursables, muchas veces constituye sistemas de producción, circulación y apropiación que cierran en sí mismos y están fuertemente direccionados a públicos habituados a esas producciones.

Jiménez, refiriéndose a las posibilidades de coordinación, articulación o abordajes inter-institucionales, sostiene que:

[...] es auspiciado y sostenido por agentes sociales que cumplen funciones públicas, es decir instituciones gubernamentales y universitarias que intervienen en la formación, producción, difusión y promoción teatral como parte de su tarea de diseño y ejecución de políticas destinadas a la búsqueda del bien común. Por tanto, el teatro es materia de atención dentro el conjunto de las políticas culturales dirigidas a diversas disciplinas artísticas, sin que exista necesariamente una instancia coordinadora de la acción pública, sino más bien distintas instituciones que confluyen en el campo teatral, operando a partir de sus propios lineamientos. (Jiménez, 2000, p.153)

Asimismo, los cambios operados en los últimos años, fundamentalmente los vinculados a las nuevas tecnologías, han puesto en cuestión, o por lo menos en discusión, ciertos formatos y prácticas culturales. Las artes escénicas, y especialmente el teatro, han sido impactadas por un proceso de las nuevas miradas en relación a la representación y la cotidianeidad. Si es cierto que los relatos en cuanto a representación y realidad se entrecruzan y mezclan en el día a día, no es de extrañar que el teatro ya no quede circunscripto al espacio teatral y que los imaginarios respecto a esas manifestaciones se impregnen en los hechos cotidianos.

Desde lo que Debord (1967) señalaba en La sociedad del Espectáculo, pasando por Baudrillard (1993) con su obra Cultura y simulacro, hasta las llamadas nuevas dramaturgias que plantean la revisión de los supuestos que han sostenido las bases de las artes escénicas, los cuestionamientos o reflexiones acerca del impacto de la estetización de lo cotidiano impregnan los debates culturales y, en particular, los relacionados con la producción, circulación y consumo de las producciones artísticas.

Lo espectacular, o en este caso lo teatral, ha inundado lo cotidiano y quizás por ello, hoy en día, todos somos espectadores de algún tipo de teatralidad deslocalizada. Pero si esto es así, ¿de qué manera el teatro como institución o espacio destinado al hecho teatral puede continuar teniendo sentido o razón de ser? Y aún más ¿De qué manera se puede hacer que los públicos o espectadores mantengan el interés por interrumpir los relatos cotidianos con la teatralidad del hecho escénico? ¿Qué se puede ver en el teatro? ¿Quién puede ver? A las artes escénicas ¿le importan las referencias culturales de los sujetos? ¿Cuál es el rol que puede asumir la educación artística? 


\section{Repensar el vínculo entre los públicos y las artes escénicas}

Habitualmente y de forma paradójica, se adjudica a los públicos la responsabilidad de todo. Es decir, si no asiste es porque no entiende, si asiste a algo que no es lo que la política cultural propone, es porque su gusto ha descendido en calidad y así en la mayoría de los enfoques. Sin embargo, pocas veces reparamos en la complejidad de nuestra contemporaneidad, también al momento de constituirnos como públicos o espectadores:

[...] más que el retiro de los públicos de todo tipo de entretenimiento o espectáculo público en vivo, sean estos del ámbito de la cultura tradicional o profesional, para ya no seguir usando el término de "alta cultura", lo que parece ocurrir es que las elecciones de los ciudadanos se han vuelto mucho más complejas. En esencia, se trata de públicos fundamentalmente eclécticos y definitivamente multimedia, que combinan lo mismo una vida hogareña totalmente influenciada por los medios, especialmente la televisión, la radio y la videocasetera, con una gama de opciones públicas de movimientos y desplazamientos hacia aquellos "eventos" que los ciudadanos juzgan dignos de ser "vivibles" o "presenciables". (Jiménez, 2000, p. 98)

Entonces quizás sea necesario colocar la atención en las dinámicas que se generan de manera mecánica o tradicional desde los ámbitos relacionados con las artes escénicas. Revisar y poner en cuestión las formas de hacer, pensar y ver a las artes escénicas.

Ya desde la década pasada Jiménez plantaba los desafíos que las artes escénicas, y en particular el teatro, afrontaba al momento de orientar sus producciones y sus maneras de hacer, hacia los públicos:

El teatro como disciplina artística se enfrenta a un contexto que exige, como condición de existencia, la búsqueda de nuevas propuestas temáticas y en el uso y expresión de su lenguaje, de la teatralidad, entendida como la esencia del arte de la representación manifiesta a través de la exploración de distintas estéticas teatrales. (Jiménez, 2000, p. 112)

Si pensamos además que desde ese entonces, el surgimiento de nuevos soportes y formas de circulación de contenidos han transformado nuestra cotidianeidad, la mirada se complejiza. Internet, streaming, redes sociales, distribución de producciones audiovisuales a bajo precio y a través de sistemas prepagos, son sólo algunos ejemplos que evidencian las formas en que estos aspectos están influenciado u orientado por los mecanismos propios de la producción y circulación teatral en nuestro medio, es decir ¿que se programa? ¿cómo? y ¿para quién?

\section{¿Quién forma a los espectadores?}

Cuando se habla de públicos en las artes escénicas, es habitual presenciar discusiones respecto a poder identificar quien es el responsable por la formación de los espectadores. Artistas, gestores, políticos, programadores y diversos actores de la actividad escénica, coinciden en que el teatro, sin actores, no existe. Sin embargo, en la práctica cotidiana, no está tan claro el concepto inverso, el que sostiene qué sin 
público, el teatro no existe. O dicho de otra forma ¿tiene sentido?

Entonces las perspectivas se entrecruzan al momento de pensar las causas de por qué no aparece o es escaso ese "gran público" al que se orienta el hecho artístico (desde el campo artístico) o las políticas culturales para hacerlo accesible que se implementan.

Retomando lo que planteaba Jiménez, comparto la noción de que:

Todavía predomina la tendencia consciente o inconsciente de pensar que la formación del público es tarea de la escuela, la familia, los medios de comunicación o de los creadores mismos, Esta visión no es del todo equívoca porque efectivamente estas instituciones y los creadores debieran tener una incidencia más profunda en dicha formación. Sin embargo, también se demanda una posición más activa en la vinculación de las instituciones que promueven el teatro con la escuela, la familia, los medios y los creadores, a fin de que efectivamente se promueva una mayor cercanía de niños, jóvenes y adultos con el arte escénico." (Jiménez, 2000, p. 168)

Esta mirada, complejiza el abordaje y coloca un elemento relevante, la necesidad de pensar estos temas con miradas interdisciplinarias y amplias, que permitan identificar y trabajar sobre nuevas perspectivas en relación a los públicos. En este sentido es clara la necesidad de trascender los ámbitos de lo artístico para ir al encuentro de enfoques que desde lo educativo permitan incorporar reflexiones en torno a los mecanismos a través de los cuales se construyen discursos en relación a las producciones estéticas y los mecanismos de apropiación, rechazo y creación que tiene los individuos que integran la sociedad.

\section{Cruzar perspectivas, articular abordajes}

Pensar los temas asociados a los públicos o espectadores viene siendo una preocupación que, como hemos visto hasta el momento, surge de la necesidad de los estudios teatrales por reivindicarse como espacio pertinente y específico para el hecho escénico.

Asimismo, se puede constatar en los abordajes puestos en relación anteriormente, un cierto desfasaje entre estas preocupaciones necesarias, y las posibilidades de problematizar los espacios desde donde surgen esas preocupaciones. Es decir, el campo de las artes escénicas se ha venido ocupando de pensar los espectadores o públicos vistos desde el escenario, pero pocas veces ha profundizado en lo que les sucede a esos sujetos más allá de la obra, el texto, el director o los actores. Y al mismo tiempo, nuestra contemporaneidad exige analizar las artes escénicas, sus formas y mecanismos, en relación con la cotidianidad con la que cotidianamente nos enfrentamos. Nuestras formas de vincularnos con las imágenes y con los artefactos estéticos han cambiado, y no solo han cambiado nuestras percepciones y formas de producción de sentido, sino que, además, han cambiado los espacios donde esos hechos suceden y las formas en que los manejamos. En este contexto es razonable pensar que las formas y mecanismos de hacer y pensar el teatro y sus dinámicas, 
también se ha modificado. ${ }^{3}$

En cierta forma los estudios de públicos nos ofrecen posibilidades de abordaje para entender el tema de la formación, ya que se puede considerar que esos procesos formativos son algo intrínseco al propio hecho de asistir a un espectáculo.

Desde esta perspectiva, cuestionar las formas en que se generan las relaciones de los espectadores con las producciones escénicas, ha sido uno de los temas que desde mediados de la década de los ` 60 del siglo pasado ha sido abordado desde diferentes ópticas.

Las preguntas formuladas acerca de los públicos han dependido de las perspectivas teóricas desde donde se formulan las prácticas y muchas veces desde las motivaciones propias del campo de las artes escénicas.

Las preguntas como: ¿Qué tipo de preguntas se proponen responder esos análisis? y ¿con qué finalidad o idea se realizan?, cobran particular relevancia al momento de poder analizar las respuestas.

Cuando Pavis (2000) se refiere al análisis de espectáculos, plantea dos tipologías: la que denomina como análisis-reportaje y análisis- reconstrucción. En los dos casos el espectador es protagonista de los procesos. Si bien propone estas dos posibilidades como válidas, metodológicamente sostiene que existen limitaciones en el reportaje, o encuesta-reportaje ya que la posibilidad de contar con datos objetivos acerca de lo que le sucede al espectador, al momento de estar frente al hecho escénico, se torna una tarea difícil en el entendido de que el formato de encuesta que puede realizarse sólo podrá generarse una vez terminado el espectáculo. Aunque se pueda realizar de forma adyacente, luego de terminado el espectáculo y si bien esto aportará datos específicos y sensaciones cuasi-espontáneas, dejará de lado muchos de los rastros que dejan las reacciones o impresiones inmediatas, ya que el sujeto mediatizará sus opiniones en función de la racionalización de sus emociones. Como bien señala Pavis (2000, p. 26):

....en la cultura occidental, el espectador de teatro (al menos, el adulto), y especialmente de teatro de texto, apenas está autorizado a manifestar en voz alta y a cuerpo descubierto sus impresiones, reacciones y comentarios; se le ruega que espere al final de la representación para expresarlo.

De esta forma se determina un rol a desempeñar por el sujeto, que será el de recibir y esperar, para luego interpretar y describir.

En cuanto al análisis-reconstrucción, refiere a un mecanismo de recopilación de datos, si se quiere emparentado con herramientas historiográficas, y coloca la atención al contexto de la representación:

[...] con la finalidad de conocer la naturaleza y la extensión del o de los contextos implicados. Se puede tratar del lugar y del público de una noche determinada, de sus expectativas, de su composición sociocultural, pero también del lugar y las circunstancias concretas de la representación. (Pavis, 2000, p. 27)

\footnotetext{
3 Al igual que lo señalaba anteriormente, teniendo en cuenta el desarrollo del tema a nivel local y el trabajo realizado en los últimos años en este campo, se incluyen en este trabajo referencias y textos publicados oportunamente en: VICCI, Gonzalo. Pensar los públicos de teatro. Conectando Audiencias - Revista de Gestión Cultural Marketing y Desarrollo de Audiencias. Madrid, n.11, p. 11-17, 2017. Acesso em: https://asimetrica.org/wp-content/uploads/2017/11/Conectando-Audiencias-11.pdf
} 
Asimismo, resulta importante incorporar un enfoque que coloque a los públicos como parte de un complejo de relaciones entre diversos agentes (Castagnino, 1956) de la creación teatral, protagonistas del hecho escénico que integran y determinan los contenidos y formas del hecho artístico: el dramaturgo; la obra misma, el texto literario; el director escénico; el actor o actriz; los accesorios escénicos; el espacio escénico y por supuesto, los públicos. La conjunción de todos ellos, las interacciones que entre ellos se producen determinan y condicionan también las formas y mecanismos a través de los cuales los públicos pueden ser incluidos o excluidos.

Jiménez apunta además la importancia de los agentes sociales externos al hecho teatral como "diseñadores y ejecutores de políticas que, enmarcan la práctica y actividad en todas sus fases: producción, difusión y consumo." (2000, p. 129) De esta forma señala en sus diferentes grados de importancia, a los productores, ya sean instituciones de carácter público o privado; las instituciones de formación; las becas y estímulos a la creación artística, la crítica especializada en artes escénicas, la investigación y sus resultados; las organizaciones gremiales y profesionales relacionadas con las artes escénicas; la legislación y por último los medios masivos de comunicación.

Esto introduce un elemento de análisis relevante y que dialoga con los abordajes vinculados a la gestión cultural y es lo que refiere al contexto y las condiciones para el desarrollo del hecho escénico.

El análisis-reconstrucción se dedica especialmente al estudio del contexto de la representación, con la finalidad de conocer la naturaleza y la extensión del o de los contextos implicados. Se puede tratar del lugar y del público de una noche determinada, de sus expectativas, de su composición sociocultural, pero también del lugar y las circunstancias concretas de la representación.” (Jiménez, 2000, p. 27)

Y en este sentido, me interesa la mirada de Rancière (2010), cuando plantea la oposición que desde los espacios de la creación teatral, marcaron, durante mucho tiempo los enfoques destinados a los públicos y de alguna forma afectan hasta el día de hoy las condiciones para los procesos de formación. De esta forma recuerda que para el teatro épico de Brecht, "el espectador debe tomar distancia" y se deberá descolocar al espectador de su lugar complaciente y pasivo hacia un rol activo de indagación y experimentación, donde participe activamente de los debates expuestos en la obra, provocando la toma de conciencia de la situación social de esos espectadores y generando las condiciones para que quieran transformarla. Contrapuesta a esta postura, el paradigma propuesto por Artaud los empuja a salir de su postura de espectadores: ya no estarán sentados frente al espectáculo, sino que ahora estarán rodeados por la acción performática, quedando dentro de la escena. Queda claro que "para uno, el espectador debe tomar distancia; para el otro, debe perder toda distancia. Para uno debe afinar su mirada, para el otro, debe abdicar incluso de la posición del que mira" (Rancière, 2010, p. 12).

Esta tensión ha estado presente durante toda la Modernidad y ha permeado los enfoques vinculados a las artes escénicas y sus públicos.

Flavio Desgranges, docente brasilero ha trabajado estos temas y ha desarrollado algunos fundamentos que aportan elementos de análisis en esta línea de reflexión. 


\section{Desde la Pedagogía del Espectador propone:}

[...] estimular en el espectador el deseo de lanzar una mirada particular hacia la obra teatral, de emprender una investigación personal en la interpretación que se hace de la obra, despertando su interés para una batalla que se libra en los campos del lenguaje" (Desgranges, 2003, p. 2)

Esto implica la necesidad de prestar atención al valor educacional intrínseco del acto de asistir a un espectáculo de artes escénicas, intentando trascender los enfoques que reducen su efecto a la trasmisión de conceptos o la dimensión didáctica de aprender teatro. Sostiene que las posibilidades de construcción de significado que pueden generarse en el momento de asistir al teatro deben ponderarse en su real dimensión:

[...] quem sabe ouvir uma história, sabe contar histórias. Quem ouve histórias, sendo estimulado a compreendê-las, exercita também a capacidade de criar e contar histórias, sentindo-se, quem sabe, motivado a fazer história. (Desgranges, 2005, p. 5)

Estas posibilidades implican un cambio de perspectiva en relación a los espectadores, mirarlos ya no como agentes pasivo-receptivos, sino que apuntando a su potencial reflexivo en relación a lo que se le coloca enfrente. Tomando como punto de partida la teatralidad, entendida como una construcción ficcional sobre la realidad, desde allí propender a la posibilidad de construcción del conocimiento por parte del sujeto espectador.

Mais do que isto, esta fundamental mudança de eixo permite-nos compreender que a participação do espectador é a de alguém que está lá para elaborar uma interpretação da obra de arte, para uma atuação que solicita sua participação criativa. Ou seja, os significados de uma obra não estão cravados nela como algo inalterável, que está lá e precisa ser entendido pelo espectador, pois se trata menos de entendimento dos significados e mais de construção de significados, que são formulados pelo espectador no diálogo que trava com a obra. (Desgranges, 2005, p. 19)

En esta línea de reflexión Alain Badiou, desde la filosofía plantea que el teatro puede permitir ver

[...] al mundo de una manera distinta que aquella que se nos pide que usemos para ver el mundo. Creo que cuando el teatro es verdaderamente intenso hay una modificación de la mirada. Luego cada uno hace con eso lo que quiere, y quizás no haga nada, pero esa no es una responsabilidad del teatro. El teatro reúne a la gente una noche. Les dirige una verdad frágil, algo en la mirada puede cambiar. A veces uno sale del teatro conmovido o pensativo, ese es el efecto más importante del teatro, cuando uno sale con cierta incertidumbre. (...) el público es parte del teatro. Entonces también es muy importante saber qué es lo que el público le está pidiendo al teatro, y quizás ahí haya una pequeña alianza posible entre el filósofo y el teatro. Quizás el filósofo pueda ayudar a que el público le pida al teatro un poco de verdad, y no simplemente un poco de espectáculo. (Badiou, 2011, p. 132)

Además, autores como Pavis ha señalado las dificultades que generan las miradas que desde los estudios sociológicos se han consolidado como plataforma para el análisis de esos públicos. Muchas veces, estos estudios están basados exclusiva- 
mente en la sistematización de datos cuantitativos sin considerar nexos que permitan relacionar esos datos con abordajes estéticos de los espectáculos como forma de acercarse desde diversas perspectivas al complejidad del tema.

Tomando estas referencias como disparadores para la reflexión, coincido con Rancière cuando sostiene que resulta necesario, poner en cuestión varios discursos y en particular

...la red de presupuestos, el juego de equivalencias y de oposiciones que sostiene su posibilidad: equivalencias entre público teatral y comunidad, entre mirada y pasividad, exterioridad y separación, mediación y simulacro; oposiciones entre lo colectivo y lo individual, la imagen y la realidad viviente, la actividad y la pasividad, la posesión de sí mismo y la alienación. (Rancière, 2010, p. 14)

Poniendo en cuestión estos supuestos, se puede avanzar en el análisis de las posibilidades de articular las artes escénicas y la educación artística en el entendido "suspender" las condiciones propuestas habitualmente al momento de pensar de qué forma los individuos pueden relacionarse con una propuesta escénica. Es decir, cruzar el camino de un lado hacia el otro, de lo que quiso decir el director o el texto hacia lo que yo puedo decirle al texto desde lo que me sucede con él.

Es claro que esto exige colocarse desde un lugar donde lo trascendente ya no sólo sea "lo teatral" sino que se amplíe a lo que sucede más allá del escenario. Y para esto también es necesario trascender la retórica de "volver protagonistas a los públicos" y poner en cuestión algunos mecanismos de trasmisión y direccionalidad que de manera casi "natural" se proponen desde diversos ámbitos.

Rancière aporta aquí, una configuración que me resulta interesante en relación a este tema, incorporando desde el Maestro Ignorante (2003) una analogía que señala las distancias planteadas sobre las relaciones pedagógicas entre maestros e ignorantes, entre los prejuicios con los que observamos a unos y a otros. Desmantelar el carácter pasivo y/o vacío del "ignorante" y el rol iluminador del maestro; modificando el tipo de relación y los recorridos a atravesar por cada uno:

La distancia que el ignorante tiene que franquear no es el abismo entre su ignorancia y el saber del maestro. Es simplemente el camino que va desde aquello que él ya sabe hasta aquello que todavía ignora, pero que puede aprender tal y como ha aprendido el resto, que puede aprender no para ocupar la posición del docto, sino para practicar mejor el arte de traducir, de poner sus experiencias en palabras y sus palabras a prueba, el arte de traducir sus aventuras intelectuales para uso de otros y de contra-traducir las traducciones que esos otros le presentan a partir de sus propias aventuras. (Rancière, 2008, p. 17)

Y me interesa esta perspectiva porque propone otra forma de colocar al espectador frente al hecho escénico. Como hemos visto, el interés por los espectadores y sus comportamientos, se ha puesto sobre la mesa ya sea desde las artes escénicas, así como desde los sistemas educativos. La retórica de ambos enfoques coloca el eje en los sujetos individuales, transformados en colectivos al momento de colocarlos frente al hecho escénico. Sin embargo, cabe preguntarse si la preocupación respecto a "los públicos" no encierra en sus dispositivos de abordaje, la consolidación de planteos que reafirman el rol pasivo de esos espectadores, solidificando esa distancia 
entre lo que "sabe" la obra, el director, los actores, el teatro y ese sujeto que (desde esta perspectiva) no sabe nada y tiene que aprenderlo todo. Como se pregunta Rancière $(2008$, p. 18-19):

¿Qué es lo que permite considerar como inactivo al espectador sentado en su asiento, si no es la radical oposición previamente aceptada entre lo activo y lo pasivo? ¿Por qué identificar mirada y pasividad, si no es por el presupuesto de que mirar quiere decir complacerse en la imagen y en la apariencia, ignorando la verdad que está detrás de la imagen y la realidad fuera del teatro? ¿Por qué asimilar escucha y pasividad, si no es por el prejuicio de que la palabra es lo contrario de la acción? Estas oposiciones - mirar/saber, apariencia/realidad, actividad/ pasividad- son todo menos oposiciones lógicas entre términos bien definidos. Definen propiamente un reparto de lo sensible, una distribución a priori de las posiciones y de las capacidades e incapacidades ligadas a dichas posiciones.

Reivindicar la posibilidad de que el espectador sea quien construye su propia dramaturgia es una opción que no es habitual. Por el contrario, la mecánica de aprender lo que quiso decir el director y entenderlo es la perspectiva que se plantea. No podemos pensar que lo que quiere el director -ya ni siquiera el autor del texto- puede llegar puro, despojado de intención y que el espectador sólo le limita a tomarlo y comprenderlo, como una trasmisión de pensamiento.

Por el contario, es mucho más probable pensar que en la superposición de distancias que se producen, entre el artista y el espectador y al mismo tiempo ente la puesta en escena en sí misma y los sujetos hagan mucho más complejo el entramado y el mecanismo real por que se constituye el sujeto espectador.

Los públicos/espectadores pueden quedar fácilmente, entonces, como los ignorantes del hecho teatral y las estrategias de acercamiento transformarse fácilmente en acciones que terminan afirmando el rol de maestros para los responsables del hecho teatral.

La perspectiva que resulta interesante entonces, es la que propone un protagonismo diferente para esos públicos, un carácter "emancipatorio", según define Rancière $(2008$, p. 19-20):

La emancipación, por su parte, comienza cuando se cuestiona de nuevo la oposición entre mirar y actuar, cuando se comprende que las evidencias que estructuran de esa manera las relaciones mismas del decir, el ver y el hacer pertenecen a la estructura de la dominación y de la sujeción. Comienza cuando se comprende que mirar es también una acción que confirma o que transforma esa distribución de las posiciones. El espectador también actúa, como el alumno o como el docto. Observa, selecciona, compara, interpreta. Liga lo que ve con muchas otras cosas que ha visto en otros escenarios, en otros tipos de lugares. Compone su propio poema con los elementos del poema que tiene delante. Participa en la performance rehaciéndola a su manera, sustrayéndose por ejemplo a la energía vital que ésa debería transmitir, para hacer de ella una pura imagen y asociar esa pura imagen a una historia que ha leído o soñado, vivido o inventado. Así, son a la vez espectadores distantes e intérpretes activos del espectáculo que se les propone.

Esta idea implica pensar que cada uno de nosotros, colocado en situación frente a una producción escénica está en condiciones de asociar y disociar discursos, signos, artefactos, producciones que le permitan generar sus propios discursos. Habitualmente realizamos esas operaciones en nuestra vida cotidiana y debería ser ra- 
zonable pensar que, al momento de plantearnos frente a una producción estética, podamos hacerlo también. Esto implica también relativizar los espacios privilegiados para la generación de discursos transformar los mecanismos de circulación de los mismos, con carácter un tanto más circular, donde:

Por todas partes hay puntos de partida, cruces y nudos que nos permiten apren-
der algo nuevo si recusamos, en primer lugar, la distancia radical, en segundo
lugar, la distribución de los roles y, en tercero, las fronteras entre los territorios.
No tenemos que transformar a los espectadores en actores ni a los ignorantes en
doctos. Lo que tenemos que hacer es reconocer el saber que pone en práctica el
ignorante y la actividad propia del espectador. Todo espectador es de por sí actor
de su historia, todo actor, todo hombre de acción, espectador de la misma historia.
(Rancière, 2008, p. 23)

Si al momento de trabajar con los públicos o espectadores, proponemos reorganizar ese escenario desde otra perspectiva, eso puede permitir mirar desde otro lugar los mecanismos de representación que las artes escénicas se proponen revisar y por tanto las posibilidades de permanecer pasivos o activos de los sujetos colocados en espectadores. Es decir, intentar aplicar otra manera de analizar lo teatral, sin renunciar al carácter colectivo que obviamente lleva intrínseco, pero poniendo atención en la posibilidad de colocar al hecho escénico en una misma posibilidad de abordaje de un texto, la lectura o una imagen, es decir (...) concebirla como una nueva escena de la igualdad en la que se traducen, unas a otras, performances heterogéneas (Rancière, 2008, p. 27-28). Pensar un espacio de intercambio entre esas performances que se presentan y los espectadores, ya no como meros "receptores", sino en la posibilidad de poder generar nuevos contextos para el contraste de discursos o formas de contar/apropiarse de una nueva realidad, moldeada por la ficción de la escena. Podríamos hablar entonces de una comunidad de narradores y de traductores donde los espectadores deberán realizar esas operaciones de traducción como forma de apropiarse de las historias narradas o interpretadas desde la escena, como forma de ponerlas en diálogo con sus propias historias y traducciones.

Este enfoque remite ineludiblemente a una mirada que se relación con la posibilidad de la educación artística, en cuanto al potencial de abordaje para provocar ese corrimiento hacia las posibilidades de interacción con ese sujeto/espectador que me parece importante pensar, tomando como punto de partida la idea de que no todos contamos con los mismo recursos para poder concretarlo; y transformando eso en el eje de la acción. Y creo importante el potencial de abordaje que relaciona las producciones escénicas y los sujetos, con la mediación de los discursos institucionales vinculados a lo artístico.

Las realidades construidas desde la ficción de lo teatral pocas veces encuentran la posibilidad real de ser discutidas, debatidas o interpeladas, generándose una profunda contradicción en un espacio consagrado a priori al sujeto espectador. En teoría sin él, no existe hecho escénico. Sin su presencia, el acontecimiento no sucede. Sin embargo, los dispositivos que sostienen los discursos que desde la escena se proyectan, habitualmente consolidan determinados enfoques que colocan la importancia en el discurso del artista. Entonces, si todo está centrado en el autor, el director, los actores, la institución o el ritual de participar colectivamente en la magia de la ficción en vivo. 
También desde la filosofía, Badiou propone poner en cuestión algunas concepciones sobre el hecho artístico y su poder de cultivar el espíritu de los individuos:

El público no va al teatro para que allí se lo cultive. No es un repollo ni un preferido. El teatro compete a la acción restringida, y toda confrontación con el índice de audiencia será para él fatal. El público va al teatro para ser sorprendido. Sorprendido por las ideas-teatro. No sale de allí cultivado sino aturdido, cansado (pensar cansa), ensimismado. No encontró, ni siquiera en la risa más enorme, con qué satisfacerse. Encontró ideas de las que él no sospechaba la existencia. (Badiou, 2011, p. 142)

Esta noción del espacio teatral dialoga con la posibilidad que presenta la experiencia estética de los sujetos, la conexión directa con sus acumulados vivenciales como disparador para la construcción de sentido. Un abordaje que tenga como eje la relación entre la producción escénica y los individuos, sus tensiones, y direccionalidades, seguramente implique generar las condiciones para el surgimiento de abordajes que dialoguen y proyecten a la educación artística en otras relaciones con las artes escénicas.

Estos abordajes teóricos, han influido en mayor o menos medida en varias experiencias implementadas en diferentes sitios geográficos, intentando instalar enfoques que aborden la formación de públicos integrando la dimensión educativa o formativa.

\section{Algunas referencias regionales}

Un antecedente claro vinculado a la preocupación que en torno a estos temas el sector de las artes escénicas ha tenido en los últimos tiempos fue el foro ESCENIUM (España). Entre 2003 y 2010 funcionó como foro de reunión de la Red Española de Teatros, Auditorios, Circuitos y Festivales. En su última edición (2010) centró las discusiones en torno a los públicos de las artes escénicas. Este abordaje, centrado en la preocupación del sector por debatir en relación a las dinámicas de circulación y accesibilidad que en torno a sus producciones generaban, dio lugar a una serie de abordajes y planteos que fueron recogidos en una publicación específica que contiene un estado del arte de la situación en ese momento en España. Si bien las situaciones locales no son comparables, ese material aporta a una mirada específica entorno al tema desde algunos de los actores directamente involucrados en la temática

Asimismo, como forma de identificar experiencias concretas de trabajo en la región, en Argentina se desarrolla desde 2005 el Programa Formación de Espectadores, emplazado en el Ministerio de Educación del Gobierno de la Ciudad de Buenos Aires, centrando su acción en las artes escénicas (más tarde comenzó a trabajar con danza contemporánea y cine). Sus impulsoras -Ana Durán y Sonia Jaroslavsky- han trabajado en un formato que vincula la producción teatral independiente y jóvenes de enseñanza secundaria, a través de un financiamiento público que permitía diagramar un programa de asistencia a diversas puestas en escena trabajando de forma paralela en la dimensión educativa. El sistema está basado en la fuerte institucionalidad, ya que constituye un programa que depende del Ministerio de Educación, seleccionando espectáculos de la cartelera de la ciudad de Buenos Aires, dedicado a la formación de 
espectadores. La dinámica de trabajo consiste en que:

[...] los alumnos de esas escuelas pasan por la experiencia de asistir a espectáculos de artes escénicas más de una vez a lo largo de su trayectoria escolar, si bien la repetición de la experiencia para cada grupo depende de la decisión de la institución educativa a la que pertenecen. En salidas programadas con más de un mes de anticipación, los jóvenes asisten a espectáculos de teatro y danza contemporáneos independientes, y a salas de proyección cinematográfica para ver cortos de directores contemporáneos independientes o films de cine de arte. Además, los docentes cuentan con actividades previas y posteriores para trabajar en el aula, que pueden adaptar a sus materias y grupos de estudiantes. (Durán, 2015, p.16)

Este programa ha profundizado desde su implementación el trabajo de vinculación entre los espacios educativos formales y las artes escénicas. Si bien los espectáculos son cerrados, es decir que son funciones específicas para los estudiantes, y esta experiencia se diferencia claramente a la de asistir a una función regular; constituye un antecedente claro de trabajo a nivel institucional.

Del mismo modo, en el Centro Gabriela Mistral (GAM) en Santiago de Chile, comenzó a implementarse desde 2010, una serie de acciones que hicieron confluir algunas iniciativas de la propia institución con políticas de impulso a generar acceso a bienes culturales en la ciudad implementadas por el gobierno. Javier Ibacache, impulsor de estos espacios, comenzó su trabajo como Director de Escuela de Espectadores entre los años 2006 y 2011 y luego tuvo a cargo la Dirección de Programación y Audiencias del Centro, de 2010 a 2016.

Este hecho no es menor, ya que la continuidad durante ese período, sumado al respaldo político explícito, permitió la puesta en marcha de un programa sustentando en el trabajo articulado de varias Áreas dentro del Centro, teniendo siempre como eje la formación de audiencias. De esta forma, tomando la problemática identificada a través de los estudios de consumo y participación cultural con que se contaban y sobre las dificultades y barreras vinculadas a la accesibilidad a las producciones del Centro, se delinearon estructuras de trabajo específicas para trabajar en esas líneas. Se identificaron segmentos de población y públicos de acuerdo a pertinencias etéreas, sociales y de género, y se crearon Departamento de Educación, Mediación y Estudios; todos ellos dependientes de la Dirección de Programación y Audiencias. Al mismo tiempo se articula el trabajo con una biblioteca que funciona en el Centro y se coordina el trabajo de comunicación y gestión de espectáculos, en función de las líneas centradas en la circulación de nuevos públicos en el Centro.

La importancia de este proyecto, entiendo que radica en el potencial de articulación y proyección que presenta la existencia de una Dirección de Programación y Audiencias, en el entendido de que permite la planificación integral de las acciones educativas, que desde las diferentes áreas de trabajo se proyectan. Sin embargo, este potencial puede transformarse también en una debilidad institucional, si pensamos que la concreción de los objetivos radica en la presencia y continuidad de la figura del Director/a, su personalidad, impronta e interesas concretos en relación al vínculo entre educación y artes escénicas. De todas formas, la experiencia desarrollada hasta el momento en el GAM constituye una referencia en relación al trabajo institucional en este campo. 


\section{Para continuar con la reflexión}

Las posibilidades de trabajo que presenta la educación artística pueden ser una espacio para comenzar a generar relaciones sinérgicas entre los innumerables actores, instituciones y situaciones que condicionan y/o posibilitan la asistencia a un espectáculo de artes escénicas. Aquello que intentamos definir como "públicos" nos exigen una mirada que trascienda el hecho artístico y sus protagonistas, generando vínculos que involucren a los sujetos, tomando como punto de partida sus experiencias.

\section{Referencias}

BADIOU, A. Imágenes y palabras: escritos sobre cine y teatro. Buenos Aires: Manantial, 2011

BOURDIEU, P. El sentido social del gusto. Elementos para una sociología de la cultura. Buenos Aires: siglo veintiuno, 2010

BOURDIEU, P. Creencia artística y bienes simbólicos: elementos para una sociología de la cultura. Aurelia Rivera, 2003

DESGRANGES, F. Quando Teatro e Educação ocupam o mesmo lugar no espaço. . São Paulo: Caminho da Artes / A Arte Fazendo Escola:, v. 1 (pp 16-35). Disponible en: http://www2.eca.usp.br/inerte/sites/default/files/media/ paper/quando_teatro_e_educacao_ocupam_o_mesmo_lugar_no_espaco.pdf . Acceso: 14 oct. 2018

DESGRANGES, F. Pedagogía del espectador: contexto de una formación. Disponible en:

http://www2.eca.usp.br/inerte/sites/default/files/media/paper/pedagogia_del_espectador._contexto_de_una_formacion.pdf Acceso: 21 jul. 2017

DURÁN, A. (2015). Ver teatro y danza por primera vez. Los jóvenes y las artes escénicas independientes en el contexto de la escuela pública. La experiencia del Programa Formación de Espectadores. (Tesis de Maestría) Flacso, Buenos Aires. Disponible en: https://repositorio.flacsoandes.edu.ec/bitstream/10469/8838/2/ TFLACSO-2015ACRD.pdf Acceso: 12 jul. 2019

JIMÉNEZ, L. Teatro y públicos. El lado oscuro de la sala. México DF: Escenologia/Conaculta, 2000

LAHIRE, B. Socializaciones y disposiciones heterogéneas: sus vínculos con la escolarización. Entrevista a Bernard Lahire. Revista Propuesta Educativa, Buenos Aires, n. 30, año 21, Jun. 2012. Disponible en <http://www.propuestaeducativa.flacso.org.ar/ 
entrevista.php?num=30>. [Entrevista realizada por Victoria Gessaghi y María Alejandra Sendón]. [ Links ]

Acceso: 20 mar. 12019

MILLER, T., \& YÚDICE, G. Política cultural. Barcelona: Gedisa, 2004

PAVIS, P. El análisis de los espectáculos. Buenos Aires: Paidós, 2000

RANCIÈRE, J. El espectador emancipado. Bueno Aires: Maniantal, 2010

YÚDICE, G. El recurso de la cultura. Barcelona: Gedisa, 2002

VICCI, Gonzalo. Formación de públicos y artes escénicas: una mirada hacia Montevideo. Congreso IberoAmericano de Ciencia, Tecnologia, Innovación y Educación. Buenos Aires (AR), 2014, p. 1-15.

VICCl, Gonzalo. Pensar los públicos de teatro. Conectando Audiencias - Revista de Gestión Cultural Marketing y Desarrollo de Audiencias. Madrid, n.11, p. 11-17, 2017. Acesso em: https://asimetrica.org/wp-content/uploads/2017/11/Conectando-Audiencias-11.pdf

Recebido em: 01/08/2019

Aprovado em: 12/10/2019 